
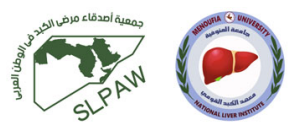

\title{
Role of transient elastography in the prediction of de novo recurrence of hepatocellular carcinoma after radiofrequency ablation: single-center Egyptian study
}

\author{
N. A. Abdelkader ${ }^{1}$, M. H. Abdelaleem¹' M. A. Abo El-maaty ${ }^{2}$, S. A. Sayed ${ }^{1}$ and H. I. Aly ${ }^{1 *}$ (D)
}

\begin{abstract}
Background: Radiofrequency is one of the curative treatment options for hepatocellular carcinoma (HCC). Despite the progressive improvements in the efficacy of radiofrequency, the survival of patients with HCC who undergo radiofrequency remains disappointing, mainly due to frequent intrahepatic recurrence of HCC after radiofrequency. We aimed to evaluate the role of transient elastography (TE) in the prediction of de novo recurrence of HCC after radiofrequency and to compare between transient elastography and the serological fibrosis indices in the prediction of de novo recurrence of HCC.

Results: Thirty HCC patients underwent baseline transient elastography for preinterventional assessment of the degree of fibrosis. Also noninvasive serum fibrosis indices were calculated from baseline data, including age platelet index (API), cirrhosis discrimination score (CDS), and FIB-4 index. Patients achieving complete response after 1 month post radiofrequency ablation were followed for further 12 months by triphasic abdominal CT scan to detect de novo lesions according to modified RECIST criteria. Baseline means of CDS, FIB4, and API were 6.03 $\pm 1.5,3.98 \pm$ 2.58 , and $1.24 \pm 1.08$, respectively. Transient elastography revealed 28 patients with F4 and only 2 patients with F3 (mean liver stiffness $22.45 \pm 10.36 \mathrm{Kba}$ ). There was a significant negative correlation between liver stiffness (LS) and de novo recurrence of HCC (mean of LS in patients with a complete response was $17.19 \pm 3.32$ while in those with de novo recurrence was $36.94 \pm 5.93$, with the best cut off value $\geq 24.65$ ( $p$ value $<0.001$ ). There was no significant correlation between CDC, FIB4, API scores, and de novo recurrence of HCC. It was found that the liver stiffness was significantly associated with the prediction of hepatic decompensation ( $p$ value $<0.001$ ). Also, liver stiffness at the cutoff value $>42.75$ ( $p$ value $=0.031$ ) was significantly associated with the prediction of 1-year mortality after radiofrequency ablation.
\end{abstract}

Conclusion: Our data suggested that liver stiffness measurement in hepatocellular carcinoma patients was a useful predictor of de novo recurrence, overall survival, and possibility of hepatic decompensation after radiofrequency ablation.

Keywords: Hepatocellular carcinoma, Radiofrequency ablation, Transient elastography, Noninvasive fibrosis indices, Liver stiffness, De novo recurrence of hepatocellular carcinoma

\footnotetext{
* Correspondence: drhebaismail105@gmail.com

${ }^{1}$ Tropical Medicine Department, Ain Shams University Hospitals, Cairo, Egypt

Full list of author information is available at the end of the article
}

(๑) The Author(s). 2021 Open Access This article is licensed under a Creative Commons Attribution 4.0 International License, which permits use, sharing, adaptation, distribution and reproduction in any medium or format, as long as you give appropriate credit to the original author(s) and the source, provide a link to the Creative Commons licence, and indicate if changes were made. The images or other third party material in this article are included in the article's Creative Commons licence, unless indicated otherwise in a credit line to the material. If material is not included in the article's Creative Commons licence and your intended use is not permitted by statutory regulation or exceeds the permitted use, you will need to obtain permission directly from the copyright holder. To view a copy of this licence, visit http://creativecommons.org/licenses/by/4.0/. 


\section{Background}

Liver cancer is considered the fifth most common cancer and also the second most frequent cause of cancerrelated death globally. Hepatocellular carcinoma represents about $90 \%$ of primary liver cancers and constitutes a major global health problem [1].

In Egypt, HCC is a significant public health problem as it is responsible for $33.63 \%$ and $13.54 \%$ of all cancers in males and females respectively [2].

RFA has been accepted as an effective curative minimally invasive treatment modality for early-stage HCC tumors (solitary tumors $5 \mathrm{~cm}$ in diameter or fewer than 3 nodules, $3 \mathrm{~cm}$ in diameter) [3].

Intrahepatic recurrence of HCC after RFA is either local tumor progression or de novo recurrence. Local tumor progression results from direct dissemination of the original tumor along the peripheral margin of the ablated lesion, while de novo recurrence accounts for the multicenter occurrence of a HCC tumor in a location away from the ablated lesion [4].

Noninvasive fibrosis indices such as aspartate aminotransferase-to-alanine aminotransferase ratio (AAR), age-platelet index (API), cirrhosis discriminant score (CDS), and FIB-4 index can play an important role in the prediction of intra-hepatic distant recurrence (IDR) of HCC following percutaneous ablation [5].

Transient elastography is a noninvasive method that uses the measurements of liver stiffness (LS) to assess the degree of hepatic fibrosis in patients with chronic liver disease. It is easily performed, gives immediate results, and has good reproducibility [6]. In addition, TE is useful for predicting de novo recurrence of $\mathrm{HCC}$ in the remnant liver as well as survival after RFA [7].

We aimed to evaluate the role of transient elastography (as an indirect indicator for the degree of liver fibrosis) in the prediction of de novo recurrence of hepatocellular carcinoma after radiofrequency ablation in hepatitis C-related hepatocellular carcinoma and, in addition, to compare between transient elastography and other noninvasive fibrosis indices in the prediction of de novo recurrence of hepatocellular carcinoma after radiofrequency ablation hepatitis C-related hepatocellular carcinoma.

\section{Methods}

This prospective cohort study was conducted on 30 HCC patients attending the HCC outpatient clinics, Ain Shams University Hospitals, Cairo, Egypt. This study was held in the period between March 2017 and May 2019. All patients enrolled were HCV-related HCC (based on AASLD guidelines 2010), Child A class, with no previous management of HCC. All patients underwent baseline transient elastography (TE) for preinterventional assessment of the degree of fibrosis (using
Echosense 502 Touch). Also noninvasive serum fibrosis indices were calculated from baseline demographic, biochemical, and radiological data, including age platelet index (API), cirrhosis discrimination score (CDS), and FIB-4 Index. Patients achieving complete response (CR) 1-month post RFA were followed for further 12 months. Triphasic abdominal CT scan was done at $1,3,6$, and12 months after intervention for the detection of any de novo lesions according to modified RECIST criteria (mRECIST). Written informed consent was obtained from all included patients. Treatment with DAAs was done according to the Egyptian guideline after curative treatment of HCC by RFA.

The exclusion criteria included other etiology of chronic liver disease rather than $\mathrm{HCV}$, any patient not fit for RFA, previous management for HCC, refusal of being enrolled in the study, and previous treatment with DAAs before RFA.

Also all patients who did not achieve complete cure (according to mRECIST criteria) 1 month after RFA were excluded.

All patients were subjected to evaluation at baseline visit through medical history and clinical examination, investigations including $\mathrm{CBC}$, liver profile, liver enzymes (ALT, AST), AFP, kidney function, and electrolytes and radiological assessment including pelvi-abdominal ultrasound and triphasic pelvi-abdominal CT scan, liver stiffness measurement using transient elastography 1 week before RFA. Age platelet index (API), cirrhosis discrimination score (CDS), and FIB-4 Index were calculated.

\section{Treatment of HCC by RFA}

RFA was carried out in the interventional radiology unit, Ain-Shams University Hospital using radionics cooled tip RF device and the session usually lasts from (12-15 min. It was performed percutaneously under ultrasound guidance. Patients should fast at least $6 \mathrm{~h}$ before the maneuver.

Follow up:

For all the patients who underwent RFA, the follow-up was done post maneuver at 1, 3, and 6 months and 1 year to determine the clinical outcome as tumor response according to the modified RECIST criteria (mRECIST) (complete response and recurrence), liver status, and survival. Only patients achieving CR 1-month post RFA were included and completed the follow-up for 12 months.

Laboratory investigations included $\mathrm{CBC}$, liver function tests, liver enzymes, and AFP. The radiological investigations included (triphasic CT or dynamic MRI).

\section{Ethical approval}

This was done according to the regulations of the research ethical committee, Faculty of Medicine, Ain 
Shams University. The number of the ethical approval is $137 / 2017(2 / 4 / 2017)$.

\section{Statistical analysis}

The collected data was revised, coded, tabulated, and introduced to a PC using a statistical package for Social Science (SPSS 25). Data was presented and suitable analysis was done according to the type of data obtained for each parameter. The mean, standard deviation $( \pm \mathrm{SD})$, and range were used to describe parametric numerical data, while the median and interquartile range (IQR) were used for non-parametric numerical data. Frequency and percentage were used to describe non-numerical data.

Chi-squared test was used in the comparison between two groups with qualitative data. Fisher's exact test was used to examine the relationship between two qualitative variables when the expected count is less than five in more than $20 \%$ of cells. The comparison between two independent groups with quantitative data and parametric distribution was done by using independent $t$ test while the comparison between two groups with nonparametric data was done by using Mann-Whitney test. Multivariate analysis for the impact of HLA mismatch was assessed using the logistic regression model. $P<$ 0.05 , significant.

\section{Results}

The demographic data of the studied patients which shows that $66.7 \%$ of patients (20 patients) were males, $33.3 \%$ (10 patients) were females, the mean age was 57.07 years \pm SD, and 22 patients $(73.3 \%)$ were from rural areas (data not shown). Baseline radiological assessment, liver stiffness, and noninvasive serological markers were shown in Table 1. Table 2 showed the laboratory investigations during 12 months of follow-up after RFA.

There was a significantly negative correlation between LS and de novo recurrence of HCC as shown in (Table 3 ) with the best cutoff value $\geq 24.65 \mathrm{kPa}$ (Fig. 1). There was no significant correlation between CDC, FIB4, API scores, and de novo recurrence of HCC (Table 3).

Table 4 shows the correlation between LS and FIB4 score and hepatic decompensation after 1 year of the first RFA. The means of LS and FIB4 in decompensated patients (in form of ascites and jaundice) were $38.53 \pm$ $8.67(p$ value $<0.001)$ and $6.05 \pm 4.71(p$ value $=0.05)$, respectively.

LS can also predict the 1-year survival where there was a statistically significant correlation between LS and 1 -year survival ( $p$ value $<0.001$ ) (Table 5$)$ with the best cutoff value $\geq 42.75$ (Fig. 2).

Regarding the correlation between LS and the serological markers, there was a statistically significant
Table 1 Baseline radiological assessment, liver stiffness, and noninvasive serological markers

\begin{tabular}{|c|c|c|c|c|c|}
\hline & Min. & Max. & Mean & SD \\
\hline & Spleen size $(\mathrm{cm})$ & 9.00 & 15.00 & 11.57 & 1.73 \\
\hline \multicolumn{2}{|c|}{ Largest lesion size $(\mathrm{cm})$} & 1.50 & 4.10 & 3.10 & 0.49 \\
\hline \multicolumn{2}{|c|}{ total tumor size $(\mathrm{cm})$} & 1.50 & 7.60 & 4.25 & 1.70 \\
\hline \multicolumn{2}{|c|}{ Liver stiffness (kPa) } & 11.80 & 46.40 & 22.45 & 10.36 \\
\hline \multicolumn{2}{|l|}{ CDS } & 4.00 & 9.00 & 6.03 & 1.50 \\
\hline \multicolumn{2}{|l|}{ FIB4 } & 1.78 & 15.26 & 3.98 & 2.58 \\
\hline \multirow{2}{*}{\multicolumn{2}{|c|}{ API }} & 0.32 & 5.54 & 1.24 & 1.08 \\
\hline & & $N$ & & $\%$ & \\
\hline \multirow[t]{2}{*}{ Fibrosis score } & F3 & 2 & & $6.7 \%$ & \\
\hline & F4 & 28 & & $93.3 \%$ & \\
\hline \multirow[t]{3}{*}{ Tumor number } & 1.00 & 19 & & $63.3 \%$ & \\
\hline & 2.00 & 10 & & $33.3 \%$ & \\
\hline & 3.00 & 1 & & $3.3 \%$ & \\
\hline
\end{tabular}

The demographic data of the studied patients which shows that $66.7 \%$ of patients (20 patients) were males, 33.3\% (10 patients) were females, the mean age was 57.07 years \pm SD, and 22 patients $(73.3 \%$ ) were from rural areas (data not shown). Table 1 showed the baseline radiological assessment, liver stiffness, and noninvasive serological markers of the included patients

correlation between LS and CDS, FIB4 score, and API, and the $p$ values were $0.01,0.01$, and 0.02 , respectively (Table 6) (Figs. 3, 4, and 5).

\section{Discussion}

Hepatocellular carcinoma is a major health problem especially in Egypt, where HCV appears to play a major role in the progression of chronic liver disease to HCC.

Radiofrequency ablation achieves a satisfactory local response rate, with more than $80 \%$ complete ablation in most studies, despite progressive improvements in the efficacy of RFA, the survival of patients with HCC who undergo RFA remains disappointing, mainly due to frequent intrahepatic recurrence of HCC after RFA.

The percentage of males in this study (66.7\%) was higher than that of females (33.3\%) with male to female ratio 2:1. An Egyptian study by Shaker et al [8] performed on 1313 patients with HCC revealed that the male to female ratio was 3.7:1.

Also, Hetta et al. [9] and Liu et al. [10] describe the male predominance of $81.9 \%$ and $92.5 \%$, respectively.

High male to female liver cancer incidence rate ratios in some countries may reflect increased exposure of known risk factors amongst men. In Egypt, for example, the primary risk factor for liver cancer, hepatitis $C$ viral infection, was widely transmitted by inoculations to control schistosomiasis, which was a disease more common amongst Egyptian men particularly those in rural areas who acquire it occupationally as farmworkers.

In this study, the age of patients ranged from 40 to 75 years with mean \pm SD $57.52 \pm 7.09$ years. This finding is 
Table 2 Laboratory investigations during 12 months of follow-up

\begin{tabular}{|c|c|c|c|c|c|c|c|c|c|c|c|c|}
\hline & \multicolumn{2}{|c|}{ Base line } & \multicolumn{2}{|c|}{1 month } & \multicolumn{2}{|c|}{3 months } & \multicolumn{2}{|c|}{6 months } & \multicolumn{2}{|c|}{12 months } & \multirow[t]{2}{*}{$F$} & \multirow[t]{2}{*}{$P$} \\
\hline & Mean & SD & Mean & SD & Mean & SD & Mean & SD & Mean & SD & & \\
\hline Serum albumin (g/dl) & 3.88 & 0.39 & 3.68 & .34 & 3.59 & 0.37 & 3.49 & 0.46 & 3.33 & 0.55 & 23.21 & $<0.001$ \\
\hline Total bilirubin (mg/dl) & 1.14 & 0.41 & 1.17 & 0.47 & 1.21 & 0.53 & 1.30 & 0.62 & 1.42 & 0.78 & 320.90 & $<0.001$ \\
\hline INR & 1.11 & 0.12 & 1.16 & 0.14 & 1.20 & 0.14 & 1.64 & 0.91 & 1.26 & 0.19 & 1.25 & 0.29 \\
\hline $\operatorname{ALT}(\mathrm{u} / \mathrm{l})$ & 43.37 & 14.18 & 47.87 & 14.55 & 44.23 & 20.73 & 45.10 & 20.08 & 44.23 & 20.73 & 1.52 & 0.20 \\
\hline AST (u/l) & 53.73 & 18.41 & 56.43 & 17.87 & 56.43 & 17.87 & 51.87 & 11.14 & 52.80 & 10.65 & 1.76 & 0.14 \\
\hline $\operatorname{TLC}\left(10^{3} / \mathrm{mL}\right)$ & 5.53 & 2.36 & 5.17 & 2.14 & 5.04 & 1.92 & 5.18 & 2.18 & 4.84 & 1.92 & 1.71 & 0.15 \\
\hline $\mathrm{HB}(\mathrm{g} / \mathrm{dl})$ & 11.95 & 1.33 & 11.75 & 1.30 & 11.46 & 1.13 & 11.27 & 1.22 & 11.17 & 1.27 & 13.15 & $<0.001$ \\
\hline Platelets $\left(10^{3} / \mathrm{mL}\right)$ & 147830 & 51700 & 143830 & 47380 & 139730 & 50330 & 135800 & 49750 & 128730 & 50.00 & 7.72 & $<0.001$ \\
\hline BUN (mg/dl) & 16.07 & 6.93 & 16.83 & 7.29 & 17.87 & 7.61 & 15.63 & 5.77 & 18.73 & 7.39 & 1.68 & 0.16 \\
\hline CR (mg/dl) & 0.92 & 0.19 & 0.97 & 0.20 & 0.99 & 0.24 & 1.00 & 0.26 & 1.08 & 0.33 & 4.004 & 0.004 \\
\hline NA (meq/l) & 136.67 & 2.09 & 136.40 & 2.46 & 135.50 & 3.15 & 134.77 & 3.45 & 133.83 & 5.75 & 6.33 & $<0.001$ \\
\hline k (meq/l) & 4.11 & .32 & 4.04 & .31 & $3.85^{b}$ & .27 & 3.86 & .35 & 3.77 & 0.44 & 8.75 & $<0.001$ \\
\hline${ }^{*} \mathrm{AFP}$ (ng/dl) & 42.00 & 54.00 & 8.50 & 6.00 & 6.50 & 6.00 & 6.30 & 5.00 & 6.05 & 59.00 & 51.64 & $<0.001$ \\
\hline
\end{tabular}

*Median and IQR

close to Hussein et al. [11], who reported that the age of patients with HCC was 40-77 years with a mean of $56 \pm$ 8.15 years.

In another Egyptian study by Shaker et al. [8], they found that the most frequent age group affected by HCC was between 51 and 60 years (45.7\%), followed by the group between 41 and 50 years (24.4\%). Also Hetta et al. [9] reported the mean age of HCC was $57 \pm 4.6$ years.

Relatively younger age in the Egyptian patients can be explained by the high prevalence of HCV among Egyptians and the occurrence of the infection at a young age.

In the current study, it was found that there was a significant negative correlation between LS measurement by TE and de novo recurrence of $\mathrm{HCC}$ with the mean of LS in patients with a complete response was (17.19 \pm $3.32 \mathrm{kPa}$ ) and the mean of LS in patients with de novo recurrence was $36.94 \pm 5.93 \mathrm{kPa}$ ), with the best cutoff value of LS to predict de novo HCC recurrence after RFA a value of $(\geq 24.65 \mathrm{kPa})$.
Conti et al. [12] reported that HCC recurrence more significantly recognized in the patients with LSM values over $21.5 \mathrm{kPa}$ before DAA therapy.

Different results were described by Lee et al. [7] who adopted a LS cutoff value of $13.0 \mathrm{kPa}$ to determine the high-risk group for recurrence.

Also Jung et al. 2012 [13] found that HCC patients with preoperative LS values more than 13.4 kappa experienced a higher incidence of HCC recurrence after curative resection than did their counterparts.

As regards the differences in the cutoff value, this phenomenon can be explained in several ways. First, in the different etiologies of CLD in the studies population, we avoided this obstacle by excluding other etiologies rather than $\mathrm{HCV}$ in our sample and also the duration of the follow-up, with a higher possibility of recurrence with a long duration of follow-up even with low LS.

In the present study, we found that the LS was significantly associated with the prediction of hepatic decompensation after RF. The LS mean in patients

Table 3 Relation between de novo HCC recurrence and noninvasive liver fibrosis tests

\begin{tabular}{|c|c|c|c|c|c|c|}
\hline & \multicolumn{4}{|c|}{ Response after 1 year } & \multirow[t]{3}{*}{$t^{*}$} & \multirow{3}{*}{$\begin{array}{l}P \\
\text { value }\end{array}$} \\
\hline & \multicolumn{2}{|c|}{$\begin{array}{l}\text { Complete response } \\
(n=22)\end{array}$} & \multicolumn{2}{|c|}{$\begin{array}{l}\text { De novo recurrence } \\
(n=8)\end{array}$} & & \\
\hline & Mean & SD & Mean & SD & & \\
\hline LS & 17.19 & 3.32 & 36.94 & 9.20 & 5.93 & $<0.001$ \\
\hline CDS & 5.77 & 1.34 & 6.75 & 1.75 & 1.63 & 0.12 \\
\hline FIB4 & 3.39 & .98 & 5.60 & 4.54 & 1.36 & 0.21 \\
\hline API & 1.02 & .65 & 1.82 & 1.73 & 1.27 & 0.24 \\
\hline
\end{tabular}

*Student $t$ test

There was a significantly negative correlation between LS and de novo recurrence of HCC with best cutoff value $\geq 24.65 \mathrm{kPa}$ (Fig. 1). There was no significant correlation between CDC, FIB4, API scores, and de novo recurrence of HCC 


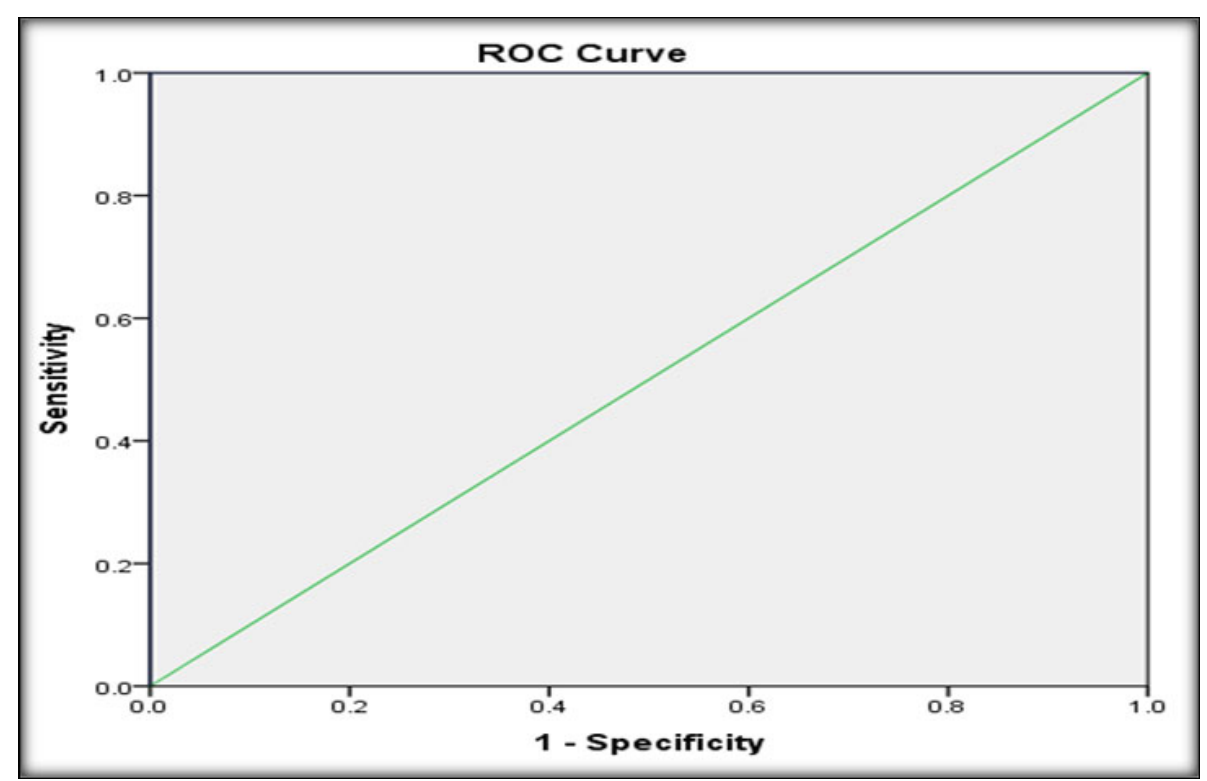

The best cut off value was $\geq 24.65$

Sensitivity $=100 \%$

Specificity $=100 \%$

Fig. 1 Validity of LS measurement in prediction of recurrence after 1 year. The best cutoff value was $\geq 24.65$, sensitivity $=100 \%$, and specificity $=100 \%$

without any manifestation of hepatic decompensation after RF was $17.3 \mathrm{kPa}$, patients complicated by with ascites only their LS mean was $(23 \mathrm{kPa})$, while those who were complicated by both ascites and jaundice during the period of follow-up was $(38.5 \mathrm{kPa})$ ( $p$ value $<0.001$ ).

Also Kang et al. [14] suggested that patients with higher LS values (13-18 and $\geq 18 \mathrm{kPa})$ had significantly higher risks of developing hepatic decompensation after RF compared to those with lower values $(<$ $13 \mathrm{kPa})(\mathrm{HR}=4.547, P=0.044$ and $\mathrm{HR}=12.446, P$ $<0.001$, respectively).
A prospective study by Robic et al. [15] demonstrated that a preoperative LS $>21.1 \mathrm{kPa}$ proved as effective as hepatic venous pressure gradient measurements to predict the clinical decompensation and liver-related events (ascites, variceal bleeding, HCC, HE, and death) after curative resection.

Two studies also looked at the evolution of liver stiffness values over time (Corpechot et al. [16], Vergniol et al. [17]) and found that patients with increasing liver stiffness (1-1.5 kPa per year) were a higher risk of developing complications, with one study estimating a 10-fold increase in complications (Corpechot et al. [16]).

Table 4 Relation between liver decompensation and noninvasive liver fibrosis tests

\begin{tabular}{|c|c|c|c|c|c|c|c|c|}
\hline & \multicolumn{6}{|c|}{ Decompensation after 1 year } & \multirow[t]{3}{*}{$F^{*}$} & \multirow{3}{*}{$\begin{array}{l}P \\
\text { value }\end{array}$} \\
\hline & \multicolumn{2}{|c|}{$\begin{array}{l}\text { No decompensation } \\
(n=22)\end{array}$} & \multicolumn{2}{|c|}{$\begin{array}{l}\text { Ascites only } \\
(n=1)\end{array}$} & \multicolumn{2}{|c|}{$\begin{array}{l}\text { Ascites and jaundice } \\
(n=7)\end{array}$} & & \\
\hline & Mean & SD & Mean & SD & Mean & SD & & \\
\hline LS & 17.31 & 3.59 & 23.00 & . & 38.53 & 8.67 & 44.70 & $<0.001$ \\
\hline CDS & 5.73 & 1.35 & 6.00 & . & 7.00 & 1.73 & 2.06 & 0.15 \\
\hline FIB4 & 3.36 & 1.00 & 3.09 & . & 6.05 & 4.71 & 3.42 & $0.05^{*}$ \\
\hline API & 1.02 & 0.65 & 1.02 & . & 1.96 & 1.82 & 2.22 & 0.13 \\
\hline
\end{tabular}

*One-way ANOVA test 
Table 5 Relation between 1-year survival and noninvasive liver fibrosis tests

\begin{tabular}{|c|c|c|c|c|c|c|}
\hline & \multicolumn{4}{|c|}{ Survival at 1 year } & \multirow[t]{3}{*}{$t^{*}$} & \multirow{3}{*}{$\begin{array}{l}P \\
\text { value }\end{array}$} \\
\hline & \multicolumn{2}{|l|}{ Alive } & \multicolumn{2}{|l|}{ Died } & & \\
\hline & Mean & SD & Mean & SD & & \\
\hline LS & 20.84 & 8.66 & 45.00 & .00 & 3.88 & $<0.001^{*}$ \\
\hline CDS & 5.96 & 1.50 & 7.00 & 1.41 & 0.94 & 0.35 \\
\hline FIB4 & 3.97 & 2.67 & 4.15 & 1.15 & 0.09 & 0.93 \\
\hline API & 1.22 & 1.11 & 1.42 & 0.41 & 0.25 & 0.81 \\
\hline
\end{tabular}

LS can also predict the 1-year survival where there was a statistically significant correlation between LS and 1-year survival $(p$ value $<0.001)$ with the best cutoff value $\geq 42.75$ (Fig. 2)

In the present study, we found that the LS at cutoff value $>42.75(p$ value $=0.031)$ and splenomegaly above $12.93 \mathrm{~cm}$ ( $p$ value $<0.021)$ were significantly associated with the prediction of the 1-year mortality after RFA.

Lee et al. [7] founded that on univariate analysis, total bilirubin, spleen size, and LS value $13.0 \mathrm{kPa}$ significantly predicted overall survival after RFA (all $p$ value $=0.05$ ).

Pang et al. [18] found that among 2052 patients (with median age 51 years, 65\% with hepatitis B or C), 87 patients $(4.2 \%)$ died or developed a hepatic complication during a median follow-up period of 15.6 months (interquartile range, 11.0-23.5 months). Patients with complications had higher median liver stiffness than those without complications $(13.5$ vs. $6.0 \mathrm{kPa} ; P<0.00005)$. The 2 -year incidence rates of death or hepatic complications were $2.6 \%, 9 \%, 19 \%$, and $34 \%$ in patients with liver stiffness $<10,10-19.9,20-39.9$, and $\geq 40 \mathrm{kPa}$, respectively $(p<0.00005)$

In our study, it was found that there was no statistically significant correlation between FIB4 index, CDS, and API and de novo recurrence of HCC.

That phenomenon was also observed in a study by Suh et al. [19], suggesting that FIB-4 has the limited capability in differentiating the risk of HCC development in contrast to LS.

Also Kim et al. [20] LS reported that TE showed significantly greater prognostic performance than FIB-4 in predicting the development of HBV-related HCC. The combined use of LS and FIB-4 did not provide additional benefit compared with the use of LS alone.

Seo et al. [5] found that FIB-4 was not significantly correlated with Intrahepatic distant recurrence after

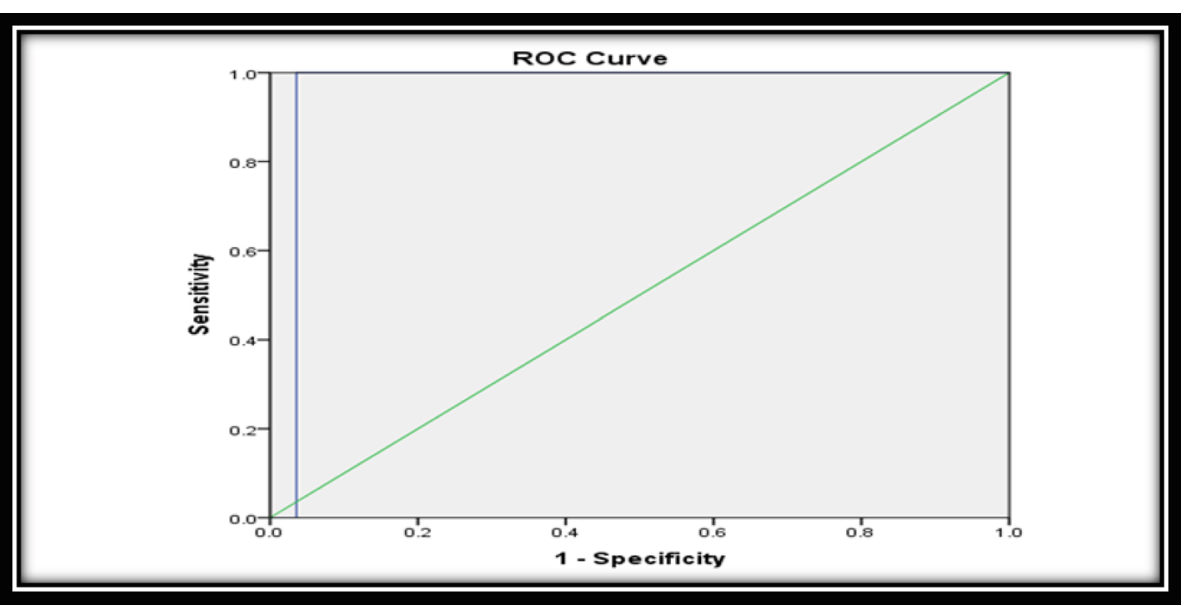

The best cut off value $\geq 42.75$

Sensitivity $=100 \%$

Specificity $=96.4 \%$

Fig. 2 Validity of LS measurement in prediction of death after 1 year. The best cutoff value $\geq 42.75$, sensitivity $=100 \%$, and specificity $=96.4 \%$ 
Table 6 Correlation between noninvasive liver fibrosis tests

\begin{tabular}{lll}
\hline & LS & \\
\cline { 2 - 3 } & $\boldsymbol{r}^{*}$ & $\boldsymbol{P}$ value \\
\hline CDS & 0.49 & $\mathbf{0 . 0 1}$ \\
Fib4 & 0.48 & $\mathbf{0 . 0 1}$ \\
API & 0.44 & $\mathbf{0 . 0 2}$ \\
\hline
\end{tabular}

$r^{*}$ (Pearson's test)

Regarding the correlation between LS and the serological markers, there was statistically significant correlation between LS and CDS, FIB4 score and API, $p$ values were $0.01,0.01$, and 0.02 , respectively

RFA of hepatitis B-related HCC in contrast to CDS and API which had a significant correlation with intrahepatic distant recurrence with ( $p$ values 0.010 and 0.004), respectively.

The current study shows the correlation between baseline FIB4 score and the occurrence of hepatic decompensation after 1 year of intervention. The mean of FIB4 score in patients complicated by ascites and jaundice was $6.05 \pm 4.71$ ( $p$ value 0.05 ).

Butt et al. [21] concluded that FIB-4 was superior to the Child-Pugh and MELD scores for prediction of incident hepatic decompensation and hepatocellular carcinoma events among chronic $\mathrm{HCV}$-infected persons. At a FIB-4 cutoff score of three, less than $1 \%$ of chronic HCV-infected patients developed hepatic decompensation or hepatocellular carcinoma.

\section{Conclusion}

In conclusion, patients with higher LS values than the cutoff value of $24.65 \mathrm{kPa}$ were at a significantly higher risk for de novo recurrence of HCC after RFA. In addition, patients with LS cutoff value $>42.75 \mathrm{kPa}$ experienced significantly decreased overall survival after RFA and increased risk of post interventional hepatic decompensation. Also there was a correlation between baseline

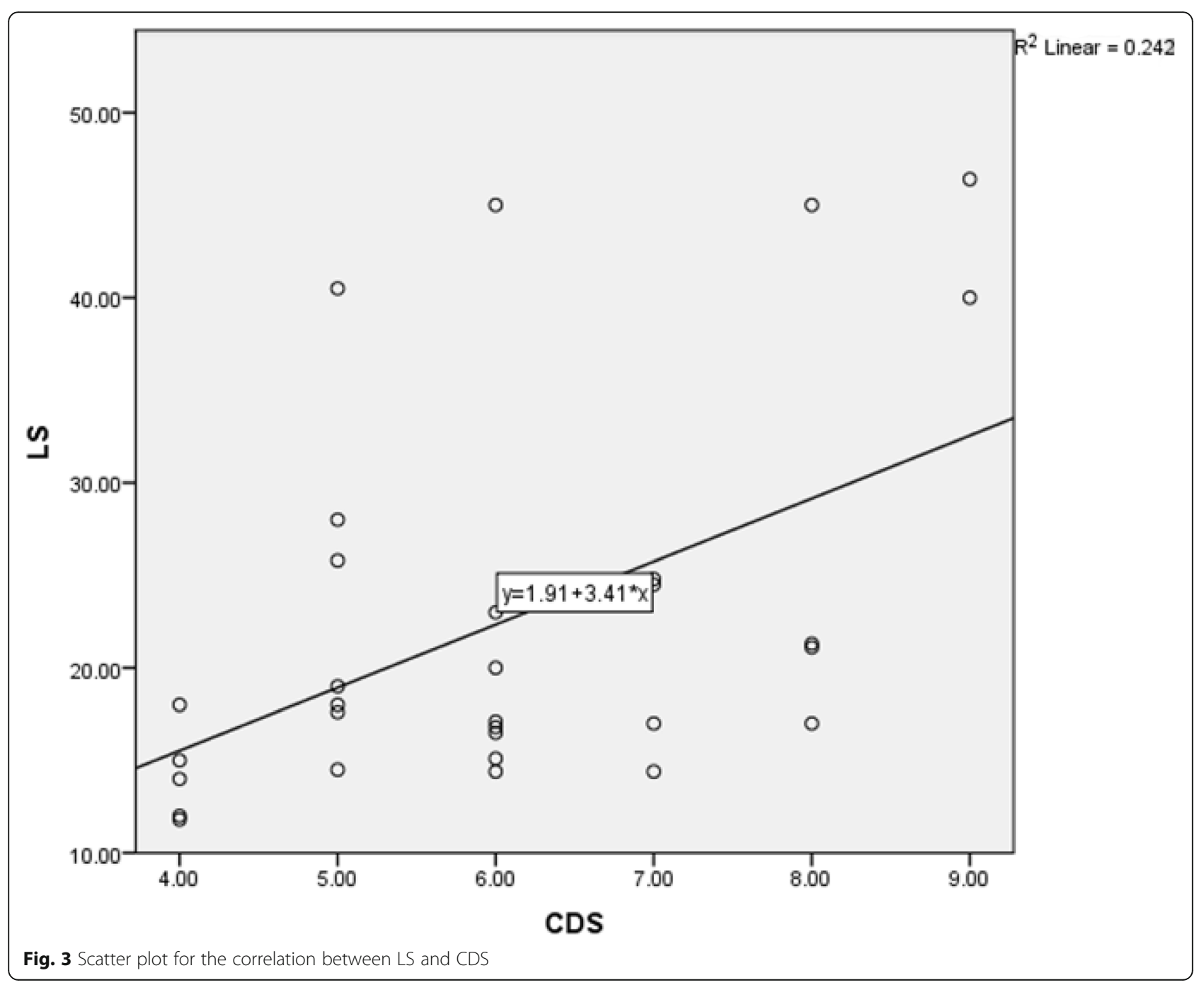




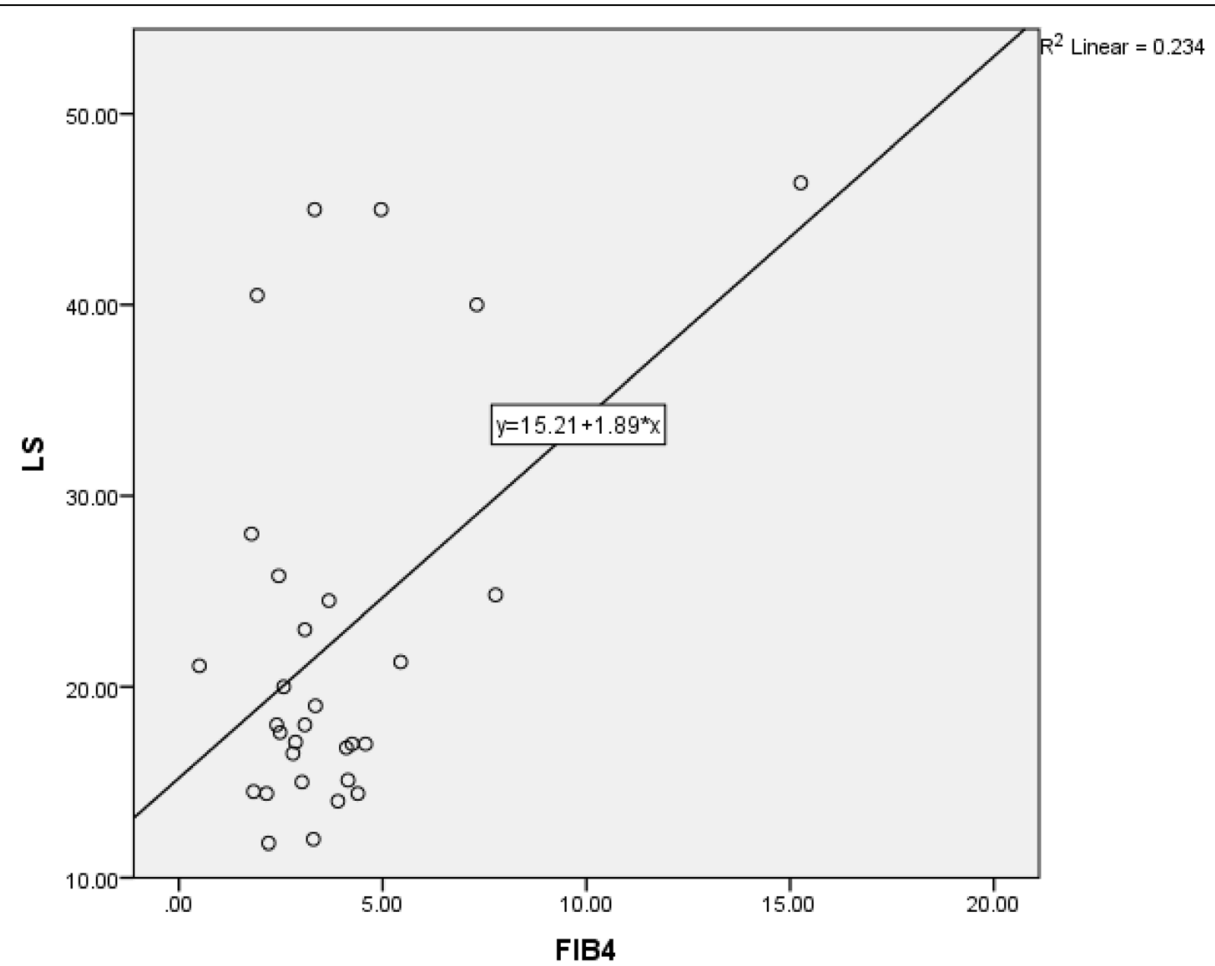

Fig. 4 Scatter plot for the correlation between LS and FIB4

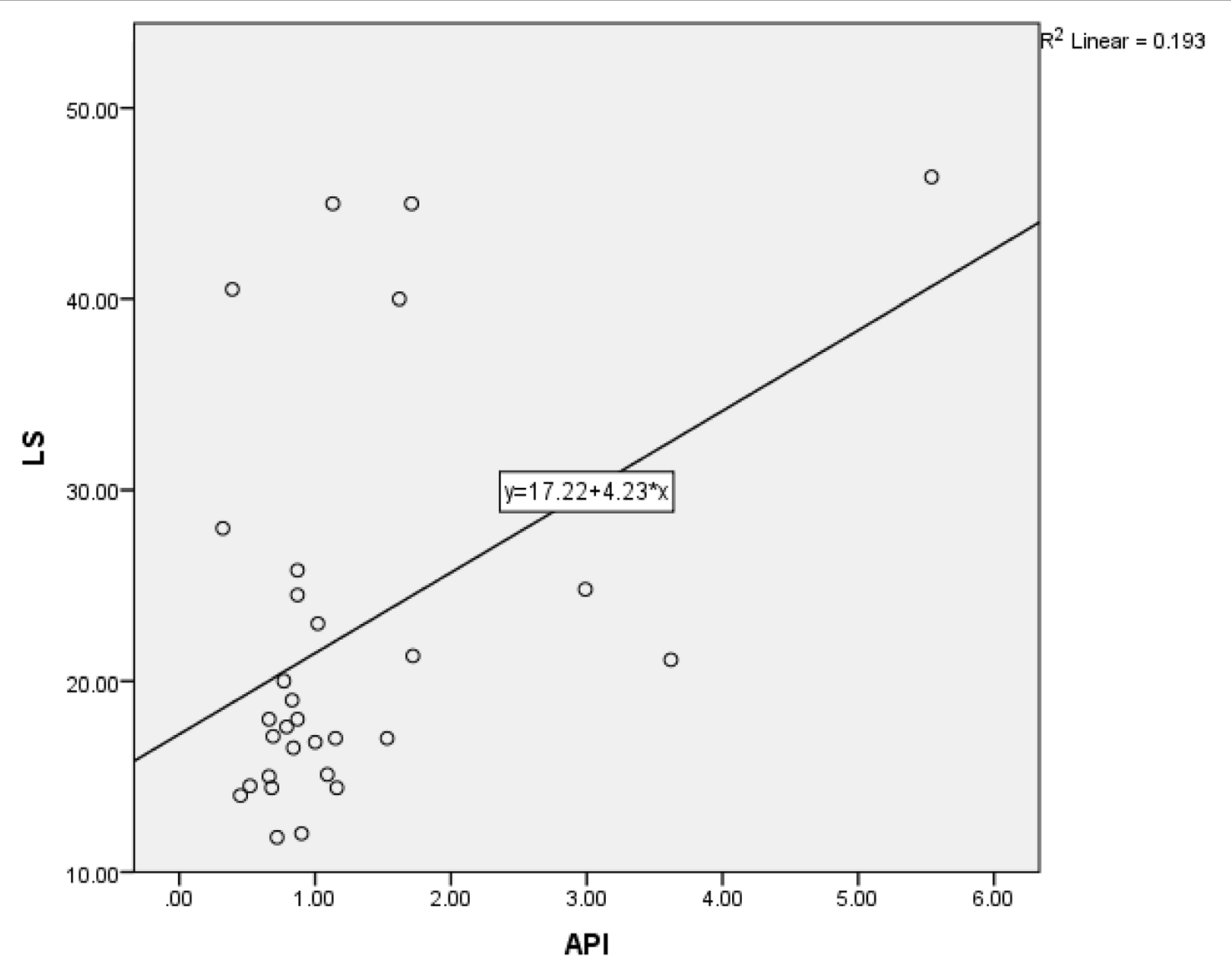

Fig. 5 Scatter plot for the correlation between LS and API 
FIB4 score and the occurrence of hepatic decompensation during 1 year of follow-up after an intervention.

Limitations of the study Although our study indicates that LS measurement by using transient elastography is useful for predicting de novo recurrence of HCC in the remnant liver as well as survival after RFA, external validation of our results in future large-scale prospective studies can expand the clinical implications of TE in a longitudinal perspective.

\section{Abbreviations}

HCC: Hepatocellular carcinoma; RFA: Radiofrequency ablation; LS: Liver stiffness; Fib4: Fibrosis 4; CDS: Cirrhosis discrimination score; API: Age-Platelet Index; MRECIST: Modified response evaluation criteria in solid tumors

\section{Acknowledgements}

Not applicable

\section{Ethical approval and consent to participate}

Written consent was taken from each patient who agreed to participate in the research process. The agreement for participation of the subjects was taken after the aim of the study has been simply explained to them prior to data collection. They were assured that anonymity and confidentiality would be guaranteed and about their right to withdraw from the study at any time without giving any reason. Values, culture, and beliefs were respected. This was done according to the regulations of the research ethical committee, Faculty of Medicine, Ain Shams University. The number of the ethical approval is $137 / 2017(2 / 4 / 2017)$.

\section{Consent for publications}

Informed consent to publish patients' data was signed by all participants prior to the beginning of the research.

\section{Declarations}

\section{Authors' contributions}

NA performed the fibroscan for all of the patients.

SA and HA collected the data and followed-up the patients.

MG performed RFA for all patients.

$\mathrm{MH}$ analyzed the data.

$\mathrm{HA}$ revised all the data and wrote the manuscript.

The authors have read and approved the manuscript.

\section{Funding}

This study was funded by the authors.

\section{Availability of data and materials}

The authors confirm that the data supporting the finding of this study are available within the article.

\section{Competing interests}

The authors declare that they have no competing interests.

\section{Author details}

${ }^{1}$ Tropical Medicine Department, Ain Shams University Hospitals, Cairo, Egypt. ${ }^{2}$ Radiodiagnosis Department, Ain Shams University Hospitals, Cairo, Egypt.

Received: 21 January 2021 Accepted: 12 April 2021

Published online: 23 April 2021

\section{References}

1. Galle PR, Forner A, Llovet JM et al (2018) EASL clinical practice guidelines: management of hepatocellular carcinoma. J Hepatol 1(2):24-27

2. Elghazaly H, Gaballah A, Bahie Eldin N (2018) Clinic-pathological pattern of hepatocellular carcinoma (HCC) in Egypt. Ann Oncol 29(15):1120-1130
3. Livraghi T, Meloni F, Di Stasi M et al (2008) Sustained complete response and complications rates after radiofrequency ablation of very early hepatocellular carcinoma in cirrhosis: is resection still the treatment of choice? Hepatology 47(1):82-89. https://doi.org/10.1002/hep.21933

4. Goldberg SN, Grassi CJ, Cardella JF et al (2009) Society of Interventional Radiology Technology Assessment Committee and the International Working Group on Image-guided Tumor Ablation. Image-guided tumor ablation: standardization of terminology and reporting criteria. J Vasc Interv Radiol 20(7):S377-S390

5. Seo JY, Kim W, Kwon JH, Jin EH, Yu SJ, Kim HY, Jung YJ, Kim D, Kim YJ, Yoon JH, Lee HS (2013) Noninvasive fibrosis indices predict intrahepatic distant recurrence of hepatitis B-related hepatocellular carcinoma following radiofrequency ablation. Liver Int 33(6):884-893. https://doi.org/10.1111/ liv.12132

6. De Lédinghen V, Vergniol J (2008) Elastographie impulsionnelle (Fibro Scan ${ }^{\circledast}$. Gastroenterol Clin Biol 32(6):58-67. https://doi.org/10.1016/S03998320(08)73994-0

7. Lee SH, Kim SU, Jang JJ et al (2015) Use of transient elastography to predict de novo recurrence after radiofrequency ablation for hepatocellular carcinoma. OncoTargets Ther 8:347-356

8. Shaker M, Abdella H, Khalifa M et al (2013) Epidemiological characteristics of hepatocellular carcinoma in Egypt: a retrospective analysis of 1313 cases. Liver Int 33(10):1601-1606. https://doi.org/10.1111/liv.12209

9. Hetta OM, Shebrya NH, Amin SK (2011) Ultrasound-guided microwave ablation of hepatocellular carcinoma: initial institutional experience. Egypt J Radiol Nucl Med 42(3-4):343-349. https://doi.org/10.1016/j.ejrnm.2011.08. 005

10. Liu Y, Zheng Y, Li S, Li B, Zhang Y, Yuan Y (2013) Percutaneous microwave ablation of larger hepatocellular carcinoma. Clin Radiol 68(1):21-26. https:// doi.org/10.1016/j.crad.2012.05.007

11. Hussein MM, Ibrahim AA, Abdella HM, Montasser IF, Hassan MI (2008) Evaluation of serum squamous cell carcinoma antigen as a novel biomarker for diagnosis of hepatocellular carcinoma in Egyptian patients. Indian J Cancer 45(4):167-172. https://doi.org/10.4103/0019-509x.44666

12. Conti F, Buonfiglioli F, Scuteri A, Crespi C, Bolondi L, Caraceni P, Foschi FG, Lenzi M, Mazzella G, Verucchi G, Andreone P, Brillanti S (2016) Early occurrence and recurrenceof hepatocellular carcinoma in HCV-related cirrhosis treated with direct-acting antivirals. J Hepatol 65(4):727-733. https://doi.org/10.1016/j.jhep.2016.06.015

13. Jung KS, Kim SU, Choi GH, Park JY, Park YN, Kim DY, Ahn SH, Chon CY, Kim KS, Choi EH, Choi JS, Han KH (2012) Prediction of recurrence after curative resection of hepatocellular carcinoma using liver stiffness measurement (FibroScan ${ }^{\oplus}$ ). Ann Surg Oncol 19(13):4278-4286. https://doi.org/10.1245/s1 0434-012-2422-3

14. Kang W, Kim SU, Ahn SH (2014) Non-invasive prediction of forthcoming cirrhosis-related complications. World J Gastroenterol 20(10):2613-2623. https://doi.org/10.3748/wjg.v20.i10.2613

15. Robic MA, Procopet B, Métivier S et al (2011) Liver stiffness accurately predicts portal hypertension related complications in patients with chronic liver disease: a prospective study. J Hepatol 55:1017-1024

16. Corpechot C, Gaouar F, El Naggar A et al (2014) Baseline values and changes in liver stiffness measured by transient elastography are associated with severity of fbrosis and outcomes of patients with primary sclerosing cholangitis. Gastroenterology. 146(4):970-979. https://doi.org/10.1053/j.ga stro.2013.12.030

17. Vergniol J, Boursier J, Coutzac C, Bertrais S, Foucher J, Angel C, Chermak F, Hubert IF, Merrouche W, Oberti F, de Lédinghen V, Calès P (2014) Evolution of noninvasive tests of liver fibrosis is associated with prognosis in patients with chronic hepatitis C. Hepatology 60(1):65-76. https://doi.org/10.1002/ hep.27069

18. Pang J, Zimmer S, Niu S et al (2014) Liver stiffness by transient elastography predicts liver-related complications and mortality in patients with chronic liver disease. PLoS One 9(4):e95776. https://doi.org/10.1371/journal.pone. 0095776

19. Suh B, Park S, Shin DW, Yun JM, Yang HK, Yu SJ, Shin Cl, Kim JS, Ahn E, Lee $\mathrm{H}$, Park JH, Cho BL (2015) High liver fibrosis index FIB-4 is highly predictive of hepatocellular carcinoma in chronic hepatitis B carriers. Hepatology 61(4): 1261-1268. https://doi.org/10.1002/hep.27654

20. Kim SU, Kim BK, Park JY et al (2016) Transient elastography is superior to FIB-4 in assessing the risk of hepatocellular carcinoma in patients with Chronic hepatitis B. Medicine 95(20):e3434 
21. Butt AA, Ren Y, Lo Re $V$ et al (2017) Comparing Child-Pugh, MELD, and FIB-4 to predict clinical outcomes in hepatitis $C$ virus-infected persons: results from ERCHIVES. Clin Infect Dis 65(1):64-72. https://doi.org/10.1093/cid/ cix224

\section{Publisher's Note}

Springer Nature remains neutral with regard to jurisdictional claims in published maps and institutional affiliations.

Submit your manuscript to a SpringerOpen ${ }^{\circ}$ journal and benefit from:

- Convenient online submission

- Rigorous peer review

- Open access: articles freely available online

- High visibility within the field

- Retaining the copyright to your article

Submit your next manuscript at $\boldsymbol{\nabla}$ springeropen.com 